\title{
Nasal-type NK/T cell lymphoma: clinical features and treatment outcome
}

\author{
J Lee', WS Kim*,I, YH Park², SH Park', KW Park', JH Kang', SS Lee', SI Lee', S-H Lee', K Kim', CW Jung', \\ YC Ahn', YH Ko ${ }^{7}$ and K Park'
}

'Division of Hematology-Oncology, Department of Medicine, Samsung Medical Center, Sungkyunkwan University School of Medicine, 50 Ilwon-dong Kangnam-ku, Seoul I 35-7 I 0, Korea; '² Department of Hematology-Oncology, Korea Cancer Center Hospital, Seoul, Korea; ${ }^{3}$ Department of HematologyOncology, Gachun Medical School Gil Medical Center, Incheon, Korea; ${ }^{4}$ Department of Pathology, Korea Cancer Center Hospital, Seoul, Korea;

${ }^{5}$ Department of Hematology-Oncology, Dankook University School of Medicine, Seoul, Korea; ${ }^{6}$ Department of Radiation Oncology, Samsung Medical Center, Sungkyunkwan University School of Medicine, Seoul, Korea; ${ }^{7}$ Department of Pathology, Sungkyunkwan University School of Medicine, Seoul, Korea

Nasal-type NK/T cell lymphoma is an increasingly recognised disease entity of aggressive clinical behaviour. The objective of this study was to investigate clinical features and treatment outcomes in patients with nasal-type NK/T cell lymphoma. From January I99| to December 2003, 26 patients diagnosed as nasal-type NK/T cell lymphoma were included in the analysis. One half of patients presented with poor performance status (ECOG $\geqslant 2$ ); $46 \%$ of patients were categorised as high intermediate or high-risk group according to IPI; and $46 \%$ of patients were diagnosed at advanced stage. The median survival for 26 patients with nasal-type NK/T cell lymphoma was 7.4 months $(95 \% \mathrm{Cl}, 0.1$, 16.9). The treatment outcome of primary anthracycline-based chemotherapy was poor: $60 \%$ CR rate in localised disease and $0 \%$ CR rate in advanced disease. After a median follow-up of 24.4 months (range 3.1-99.0) in patients with localised disease who had achieved a CR (range 29.6- 165.7), three patients (50.0\%) developed disease recurrence at 6.I , 21.8 , and 52.I months, respectively, and all patients presented with locoregional failure. The predictive factors for poor survival were of age greater than 60, advanced stage and poor performance in multivariate analysis. In conclusion, Nasal-type NK/T cell lymphomas showed a poor response to the conventional anthracycline-based chemotherapy, and thus an investigation for an innovative therapy is urgently needed to improve survival in these patients.

British Journal of Cancer (2005) 92, 1226-1230. doi:I0.1038/sj.bjc.6602502 www.bjcancer.com

Published online 29 March 2005

(c) 2005 Cancer Research UK

Keywords: extra-nasal; natural killer cell lymphoma; treatment

Extranodal NK/T cell lymphoma is subcategorised into nasal and nasal-type NK/T cell lymphomas according to the major sites of anatomic involvement (Jaffe et al, 1996, 1999). The nasal NK/T cell lymphoma commonly presents with midline facial destructive disease, shows a strong association with Epstein - Barr virus (EBV), and occurs prototypically within the nasal cavity (Liang et al, 1995; Jaffe, 1996; Jaffe et al, 1996; Hirakawa et al, 1999; Cheung et al, 2002). It was previously categorised as angiocentric lymphoma in the Revised European-American Lymphoma (REAL) classification, and has been recently recategorised as extranodal NK/T cell lymphoma in the new WHO classification of lymphoid neoplasms (Harris et al, 1994; Jaffe, 1996; Jaffe et al, 1996; Harris et al, 1999).

In limited cases, NK/T cell lymphoma may predominantly occur in extranasal sites without involvement of nasal cavity or nasopharynx. It is not until recently that this form of extranodal lymphoma has been recognised to present with highly aggressive clinical course and share similar immunophenotypic profile with nasal NK/T cell lymphoma (Kern et al, 1992; Wong et al, 1992). This disease entity was recognised as an independent form of

*Correspondence: Dr WS Kim; E-mail: wskimsmc@smc.samsung.co.kr Received 26 August 2004; revised 7 February 2005; accepted 7 February 2005; published online 29 March 2005 disease and defined as nasal-type NK/T cell lymphoma in Hong Kong workshop in 1994 (Jaffe, 1996). The largest series on nasaltype NK/T cell lymphoma reported a retrospective review of 34 cases and observed that these patients were often refractory to combined chemotherapy (Chan et al, 1997). As most published reports on NK/T cell lymphomas mainly focus on the clinicopathologic features, the role of chemotherapy on the clinical outcome as well the optimal treatment approach needs to be defined. None of the previous studies analysed the treatment outcome of primary chemotherapy in nasal-type NK/T cell lymphoma.

As nasal-type NK/T cell lymphoma is known to be one of the most aggressive lymphomas, it is imperative to offer an appropriately aggressive treatment at an early stage of disease. We report the clinical features and treatment outcome of nasal-type NK/T cell lymphoma patients, especially after anthracycline-based chemotherapy.

\section{PATIENTS AND METHODS}

In total, 26 patients, who were diagnosed as nasal-type NK/T cell lymphoma between January 1991 to December 2003, were included in the analysis. All patients were histologically confirmed of NK/T 
cell lymphoma, according to WHO classification and had proven NK/T cell type by immunohistochemistry, flow cytometry, or EBV in situ hybridisation. Nasal NK/T cell lymphoma, blastic NK-cell leukaemia, aggressive NK cell lymphoma/leukaemia, and peripheral $\mathrm{T}$ cell lymphoma, unspecified were excluded from the analysis. Nasal NK/T cell lymphoma was defined as lymphomas occurring within nasal cavity and/or upper aerodigestive tract such as oral cavity, palate, larynx, pharynx, and tonsil. Nasal-type NK/T cell lymphoma was defined as those primarily involving outside nasal cavity/nasopharynx or upper aerodigestive tract. Patients with lesions within the nasal cavity and secondary spread to other organs were categorised as nasal NK/T cell lymphoma and were excluded from the analysis. The pathologic diagnosis of nasal-type NK/T cell lymphoma was based on the following criteria: expression of cytoplasmic CD3 and CD56 and positivity for EBV in situ hybridisation. If EBV in situ hybridisation was negative, the immunophenotype studies should demonstrate cytoplasmic CD3 expression and positive cytotoxic molecules such as TIA-1.

The following clinical data were collected from the record: patient demographics, complete blood count, lactic dehydrogenase (LDH) level, Ann Arbor stage, IPI, bone marrow findings, the presence of B symptoms, performance status, date of diagnosis, type of treatment, treatment response, date of relapse, date of last follow-up, live status, and cause of death.

\section{Histology}

In all cases, haematoxylin-eosin-stained slides were reviewed by two pathologists. Immunophenotyping was performed using a panel of monoclonal antibodies including antibodies against cytoplasmic CD3 (Dakopatts, Copenhagen, Denmark), CD20 (Dakopatts), CD56 (Monosan, Uden, the Netherlands), and TIA-1 (Coulter, Hialeah, FL, USA). EBV RNA was detected by an in situ hybridisation technique. Briefly, paraffin sections were pretreated with xylene, followed by treatment with proteinases $\mathrm{K}$ and hybridised with FITC-conjugated EBV oligonuecleotides (Dakopatts) complementary to the nuclear RNA portion of the EBER 1 and 2 genes.

\section{Treatment}

The anthracycline-based chemotherapy regimen used were as following: CHOP (cyclophosphamide, doxorubicin, vincristine, prednisolone), dose-escalated CHOP(deCHOP), COPBLAM (cyclophosphamide, vincristine, prednisone, bleomycin, doxorubicin, procarbazine), and EPOCH (etoposide, doxorubicin, vincristine, cyclophosphamide, prednisolone). The nonanthracycline-based chemotherapy regimens were DICE (dexamethasone, ifosfamide, cisplatin, etoposide) and CVP (cyclophosphamide, vincristine, prednisone). CHOP regimen consisted of cyclophosphamide (750 $\mathrm{mg} \mathrm{m}^{-2}$ given intravenously on day 1 ), doxorubicin (50 $\mathrm{mg} \mathrm{m}^{-2}$ given intravenously on day 1$)$, vincristine $\left(1.4 \mathrm{mg} \mathrm{m}^{-2}\right.$ but not more than $2.0 \mathrm{mg}$ given intravenously on day 1 ), and prednisolone (100 mg daily, given orally on days 1-5). Doseescalated CHOP consisted of cyclophosphamide $\left(1250 \mathrm{mg} \mathrm{m}^{-2}\right.$ given intravenously on day 1$)$, doxorubicin $\left(75 \mathrm{mg} \mathrm{m}^{-2}\right.$ given intravenously on day 1$)$, vincristine $\left(1.4 \mathrm{mg} \mathrm{m}^{-2}\right.$ but not more than $2.0 \mathrm{mg}$ given intravenously on day 1$)$, and prednisolone $(100 \mathrm{mg}$ daily, given orally on days 1-5) with G-CSF support until neutrophil count recovery. The chemotherapy cycles were repeated at 21-day intervals. The alternative regimens were COPBLAM (cyclophosphamide $400 \mathrm{mg} \mathrm{m}^{-2}$, vincristine $1.0 \mathrm{mg} \mathrm{m}^{-2}$, and doxorubicin $50 \mathrm{mg} \mathrm{m}^{-2}$ intravenously on day 1 , bleomycin $15 \mathrm{mg}$ intravenously on day 14 , procarbazine $100 \mathrm{mg} \mathrm{m}^{-2}$ and prednisolone $40 \mathrm{mg} \mathrm{m}^{-2}$ daily, given orally on days $1 \pm 10$ ); and $\mathrm{EPOCH}$ (etoposide $50 \mathrm{mg} \mathrm{m}^{-2}$, vincristine $0.4 \mathrm{mg} \mathrm{m}^{-2}$, and doxorubicin $10 \mathrm{mg} \mathrm{m}^{-2}$, all given in a continuous infusion on days $1-4$ with cyclophosphamide $750 \mathrm{mg} \mathrm{m}^{-2}$ i.v. bolus on day 6 and oral prednisone $60 \mathrm{mg} \mathrm{m}^{-2}$ on days 1-6). DICE regimen consisted of dexamethasone $10 \mathrm{mg}$ q.i.d., ifosfamide $1 \mathrm{~g} \mathrm{~m}^{-2}$, cisplatin $25 \mathrm{mg} \mathrm{m}^{-2}$, etoposide $100 \mathrm{mg} \mathrm{m}^{-2}$, and mesna uroprotection daily $\times 4$ given every 28 days, and CVP was cyclophosphamide $1000 \mathrm{mg} \mathrm{m}^{-2}$ i.v. on day 1 , vincristine $1.4 \mathrm{mg} \mathrm{m}^{-2}$ (max. $2 \mathrm{mg}$ ) i.v. on day 1 , and prednisolone $100 \mathrm{mg}$ daily, given orally on days $1-5$.

In patients with localised disease, involved-field radiotherapy (IFRT) was given at physician's discretion following chemotherapy. IFRT began 3 weeks after the completion of planned chemotherapy. The total radiotherapy dose was $45 \mathrm{~Gy}$ administered over 5 weeks by conventional fractionation schedule $(1.8 \mathrm{~Gy} /$ fraction, 5 fractions/week) to the prechemotherapy gross disease extent.

\section{Response criteria}

The treatment response was assessed according to standard response criteria (Cheson et al, 1999). Complete remission (CR) was defined as no evidence of residual disease; partial response (PR) was at least a $50 \%$ reduction in the tumour burden from the onset of treatment; no response was less than $50 \%$ reduction in tumour burden or disease progression. CR/unconfirmed (Cru) was defined as the reduction of mass by more than $75 \%$ with no newly developed lesions. Assessment of response was evaluated by follow-up clinical, radiologic, and laboratory studies as determined relevant by the clinician.

\section{Statistical analysis}

Survival rates were compared for statistical differences by using log-rank analysis. $P$-values less than 0.05 were considered statistically significant and all $P$-values correspond to two-sided significance tests. Overall survival (OS) and disease-free survival (DFS) were estimated using the Kaplan-Meier product-limit method. Disease-free survival was calculated from the date treatment began to the date when the disease progression was recognised or the date of the last follow-up visit. Overall survival was measured from the date of diagnosis to the date of death or the last follow-up visit.

\section{RESULTS}

\section{Clinical characteristics and os}

The clinical characteristics of patients with nasal-type NK/T cell lymphoma are listed in Table 1. The median age at diagnosis was 50 years (range, 22-81 years). There was a male preponderance with a male to female ratio of $2.3: 1$. One half of patients presented with poor performance status (ECOG $\geqslant 2$ ), $46 \%$ of patients were categorised as high intermediate or high-risk group according to IPI, and $46 \%$ of patients were diagnosed at advanced stage. B symptoms occurred in $11(42.3 \%)$ patients. An OS curve is shown in Figure 1 for all patients $(n=26)$. The median survival for patients with nasal-type NK/T cell lymphoma was 7.4 months $(95 \%$ CI, 0.1, 16.9). The median follow-up duration for living patients was 53.4 months with a range of 29.6-99.0 months. The major sites of involvement were as following: gastrointestinal tract $(n=8)$, cutaneous $(n=7)$, soft tissues $(n=8)$, pleura $(n=1)$, and liver $(n=2)$ (Table 2).

\section{Localised nasal-type NK/T cell lymphoma}

Of 14 patients with early stage nasal-type NK/T cell lymphoma (stage I and II), 10 patients received primary anthracycline-based chemotherapy (nine CHOP, one COPBLAM). Two patients underwent primary surgical resection due to their initial presentation of bowel obstruction and received CHOP chemotherapy as postoperative treatment. One patient presented with soft tissue mass at 
calf and achieved CR following mass excision and IFRT but experienced local relapse. One remaining patient had best supportive care due to old age and patient's refusal for further treatment. Of 10 patients who received anthracycline-based chemotherapy with or without IFRT as a primary treatment, six patients $(60.0 \%)$ achieved CR. After a median follow-up of 24.4 months of these patients (range 3.1-99.0), three patients $(50.0 \%$ ) developed disease recurrence at 6.1, 21.8, and 52.1 months, respectively. The patterns of recurrence were locoregional in all three patients. Three patients, who achieved CR after CHOP chemotherapy followed by IFRT, remain alive in remission at 29.6, 30.5, and 99.0 months, respectively. Of five patients who were refractory to the initial anthracycline-based chemotherapy, two patients died after two and six cycles of CHOP chemotherapy, respectively, and three patients received salvage treatment with either high-dose cytarabine or ifosfamide-based chemotherapy. All of the five anthracycline-refractory patients died between 3.1 and 72.8 months.

Table I Patient characteristics

\begin{tabular}{|c|c|c|}
\hline & \multicolumn{2}{|c|}{ Patients } \\
\hline & No. & $\%$ \\
\hline $\begin{array}{l}\text { Median age (years), range } \\
\text { Sex (M:F) }\end{array}$ & \multicolumn{2}{|c|}{$\begin{array}{c}50(22-8 \mid) \\
\mid 8: 8\end{array}$} \\
\hline Performance status $(E C O G \geqslant 2)$ & 13 & 50.0 \\
\hline B symptom $(+)$ & 11 & 42.3 \\
\hline Stage I, II & 14 & 53.9 \\
\hline \multicolumn{3}{|l|}{$|P|$} \\
\hline Low & 7 & 26.9 \\
\hline Low intermediate & 7 & 26.9 \\
\hline High intermediate & 6 & 23.1 \\
\hline High & 6 & 23.1 \\
\hline LDH (high) & 16 & 61.5 \\
\hline EBV ISH (+) & $18 / 23$ & 78.3 \\
\hline BM involvement & 2 & 7.7 \\
\hline
\end{tabular}

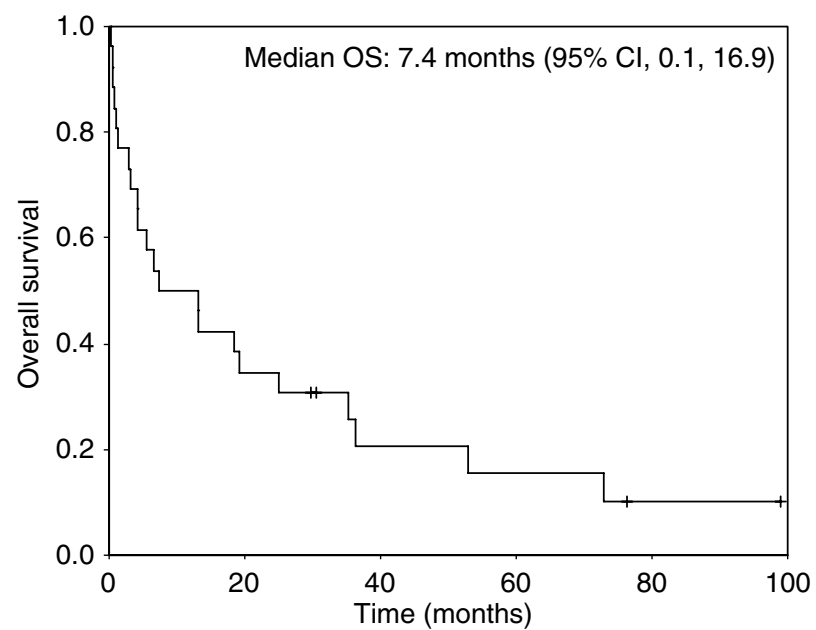

Figure I Overall survival according to subtypes.

Table 2 Treatment outcome

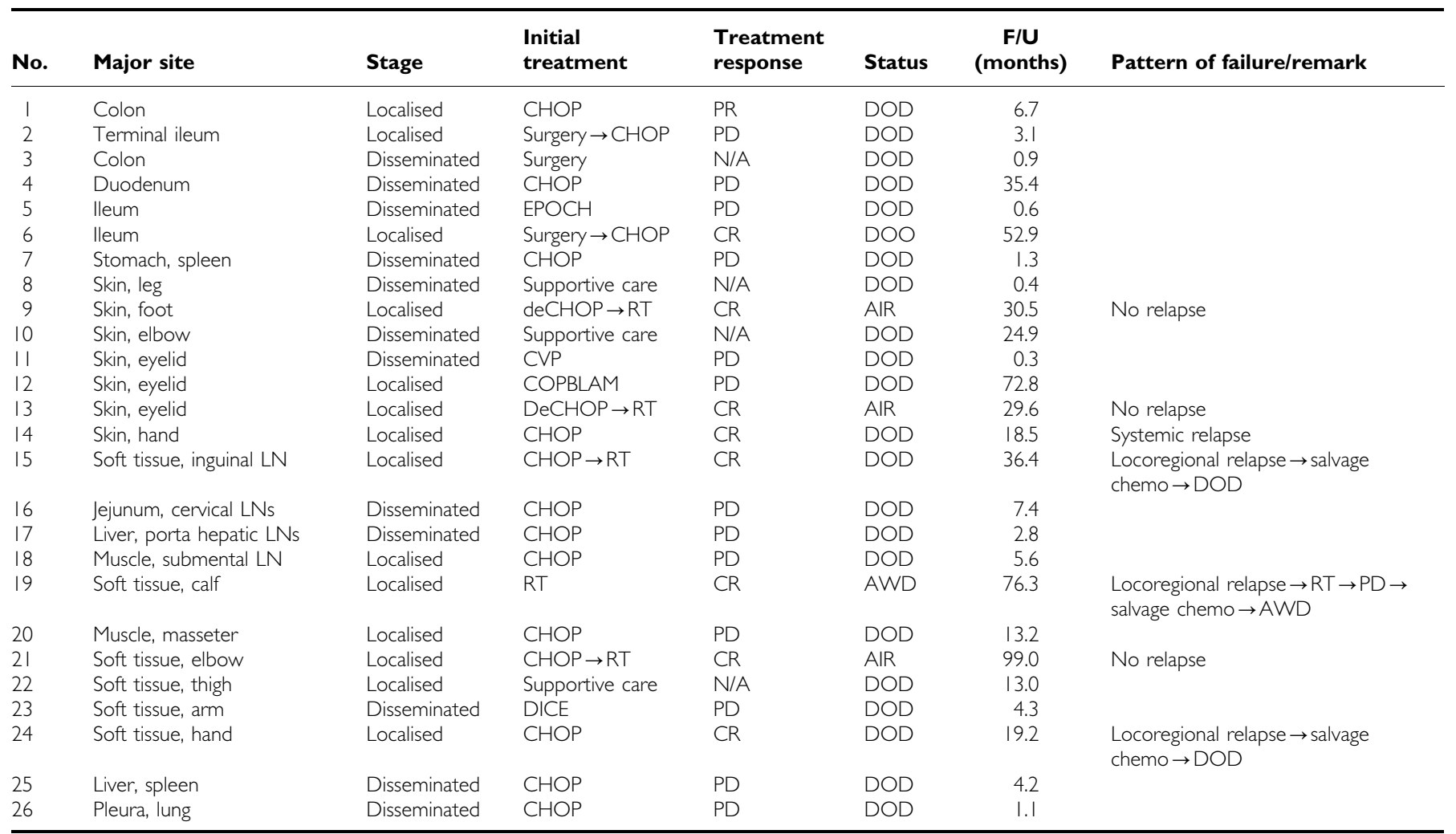

$\mathrm{DOD}=$ dead of disease; $\mathrm{DOO}=$ dead of other cause; $\mathrm{AIR}=$ alive in remission; $\mathrm{AWD}=$ alive with disease; $\mathrm{CHOP}=$ cyclophosphamide, doxorubicin, vincristine, prednisolone; dose-escalated $\mathrm{CHOP}=$ deCHOP; COPBLAM = cyclophosphamide, vincristine, prednisone, bleomycin, doxorubicin, procarbazine; $E P O C H=$ etoposide, doxorubicin, vincristine, cyclophosphamide, prednisolone; DICE = dexamethasone, ifosfamide, cisplatin, etoposide; CVP = cyclophosphamide, vincristine, prednisone. 
Table 3 Prognostic factors

\begin{tabular}{lcc}
\hline & \multicolumn{2}{c}{ OS (P-value) } \\
\cline { 2 - 3 } Variables & Univariate analysis & Multivariate analysis \\
\hline Age $(>60)$ & 0.0283 & 0.0261 \\
Sex & 0.7947 & 0.4681 \\
PS (ECOG 2-4) & 0.0004 & 0.0031 \\
B symptom & 0.0202 & 0.6352 \\
LDH & 0.0822 & 0.3851 \\
IPI & 0.0018 & 0.2692 \\
BM (+) & 0.0161 & 0.2121 \\
EBV (+) & 0.7008 & 0.7310 \\
Stage (disseminated) & 0.0003 & 0.0017 \\
\hline
\end{tabular}

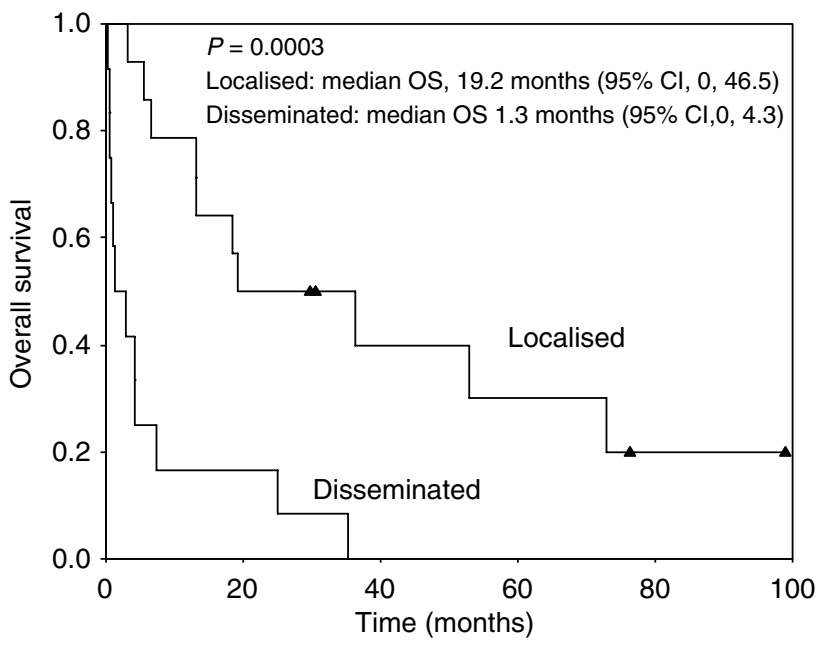

Figure 2 Overall survival curve according to stage.

\section{Disseminated nasal-type NK/T cell lymphoma}

In total, 12 patients $(46.2 \%)$ presented with disseminated disease and seven patients received primary anthracycline-based chemotherapy (six CHOP, one EPOCH). All seven patients developed progressive disease despite of chemotherapy and died of disease. Of these seven patients, only two patients $(28.6 \%)$ have tolerated more than two cycles of chemotherapy, while four patients $(57.1 \%)$ died after one cycle of chemotherapy. Of the remaining five patients, two patients received nonanthracycline based chemotherapy (DICE and CVP) and three patients did not receive chemotherapy. Of 12 patients with disseminated disease, six patients $(85.7 \%)$ died of disease progression or treatment related complications within less than 7 months from the date of diagnosis.

\section{Clinical predictors of survival}

The important clinical factors predicting reduced survival were age greater than 60 , poor performance, presence of B symptoms, high IPI score, advanced stage, and bone marrow involvement at univariate level (Table 3, Figure 2). In stepwise Cox multivariate regression analysis, age greater than 60 , advanced stage, and poor performance had an independent influence on poor survival.

\section{DISCUSSION}

As nasal-type NK/T cell lymphoma has recently been recognised as an independent disease entity, neither the clinical features nor the optimal therapeutic approach has been defined yet. This report is the first paper to describe clinical behaviour and the treatment outcome exclusively in patients with nasal-type NK/T cell lymphoma. We analysed the treatment outcome of anthracycline-based chemotherapy (CHOP in 15 out of 17 patients, $88.2 \%)$ in this rare subtype of lymphoma.

Nasal-type NK/T cell lymphoma has been introduced at the Hong Kong workshop held in 1994 (Jaffe et al, 1996). This disease entity encompasses all NK/T cell lymphomas occurring outside nasal cavity and nasopharynx and is notorious for its aggressive clinical course. The definition of nasal-type is confusing, which resulted in different categorisation by various institutions (Kern et al, 1992; Wong et al, 1992; Peiper, 1993; Nakamura et al, 1995; Jaffe et al, 1996, 1999; Kobashi et al, 1996; Chan et al, 1997; Bekkenk et al, 2004; Ko et al, 2004). We defined nasal-type lymphoma as lesions primarily involving skin, soft tissues, visceral organs such as liver, spleen, and gastrointestinal tract without any lesions within the nasal cavity and/or upper aerodigestive tract such as oral cavity, tonsil, pharynx, and larynx.

Several studies have reviewed small series of patients and suggested an early administration of highly aggressive treatment for nasal-type NK/T cell lymphoma. Chan et al (1997) summarised 32 cases of nasal-type NK/T cell lymphoma and described the aggressive clinical course of the disease. Although survival data or detailed treatment outcome were not provided, they found the disease to be refractory to combination chemotherapy since 24 patients died in 1 week to 3 years, with a median of 3.5 months despite of chemotherapy. Mraz-Gernhard et al (2001) reported 30 cases of nasal-type NK/T cell lymphomas with cutaneous presentation and primary anthracycline-based chemotherapy was administered in 10 patients, where five patients achieved CR with short duration of response ranging from 1.5 to 4 months. A small retrospective review on the treatment outcome of the first-line anthracycline-based chemotherapy in extranodal NK/T cell lymphoma reported a low CR rate of $28.6 \%$ in 14 cases of nasaltype NK/T cell lymphoma patients (Kim et al, 2003). The Dutch group recently analysed 38 nasal-type NK/T cell lymphoma patients from the literature, of whom $70 \%$ received CHOP-like chemotherapy and showed a median survival of 6 months (Bekkenk et al, 2004). This group concluded that doxorubicinbased chemotherapy was insufficient for effective disease control for both nasal and nasal-type NK/T cell lymphomas.

Likewise, the median survival of 26 nasal-type NK/T cell lymphoma patients was only 7.4 months (95\% CI, 0.1, 16.9) in our series. The overall response to the primary anthracyclinebased chemotherapy in 17 patients was poor (overall CR rate $35.3 \%, 95 \%$ C.I. $12.6,58.0$ ). We have previously reported that three or four cycles of CHOP followed by IFRT was not satisfactory for treating patients with localised nasal NK/T cell lymphoma due to low CR rate (six of 15 patients, $40 \%$, Kim et al, 2001). Owing to the limitations of a retrospective study and the small number of patients in the series, conclusions on the optimal treatment or pattern of failure cannot be made. In localised disease, all three relapsed patients showed local failure while two live patients in remission had received IFRT following four cycles of CHOP. This may suggest a possible role of IFRT for local disease control in nasal-type NK/T cell lymphoma, although IFRT alone has shown to be unsatisfactory due to frequent systemic failures (Kim et al, 2000).

One possible explanation for the resistance to the standard chemotherapy would be a high expression of multidrug resistance (P-glycoprotein positive) phenotype in NK/T cell lymphoma patients. One study reported that an immunohistochemical staining against MDR in $28 \mathrm{NK} / \mathrm{T}$ cell lymphoma patients with primary cutaneous involvement revealed $78.6 \%$ MDR positivity, although its clinical correlation is yet to be defined (MrazGernhard et al, 2001).

Considering the poor outcome of standard treatments, few groups designed an innovative therapy. The Chinese group 
reported a successful treatment in a patient with advanced nasaltype NK/T cell lymphoma with four courses of l-asparaginase combined with vincristine and prednisone as an induction therapy followed by six courses of CHOP as a consolidation treatment (Obama et al, 2003). Lee et al (2004) recently administered a combination chemotherapy of ifosfamide, methotrexate and etoposide in six extranasal NK/T cell lymphoma patients and reported a $20 \%$ CR rate.

\section{REFERENCES}

Bekkenk MW, Jansen PM, Meijer CJ, Willemze R (2004) CD56+ hematological neoplasms presenting in the skin: a retrospective analysis of 23 new cases and 130 cases from the literature. Ann Oncol 15: 1097-1108

Chan JK, Sin VC, Wong KF, Ng CS, Tsang WY, Chan CH, Cheung MM, Lau WH (1997) Nonnasal lymphoma expressing the natural killer cell marker CD56: a clinicopathologic study of 49 cases of an uncommon aggressive neoplasm. Blood 89: $4501-4513$

Cheson BD, Horning SJ, Coiffier B, Shipp MA, Fisher RI, Connors JM, Lister TA, Vose J, Grillo-López A, Hagenbeek A, Cabanillas F, Klippensten D, Hiddemann W, Castellino R, Harris NL, Armitage JO, Carter W, Hoppe R, Canellos GP (1999) Report of an international workshop to standardize response criteria for non-Hodgkin's lymphomas. J Clin Oncol 17: 1244-1253

Cheung MM, Chan JK, Lau WH, Ngan RK, Foo WW (2002) Early stage nasal NK/T-cell lymphoma: clinical outcome, prognostic factors, and the effect of treatment modality. Int J Radiat Oncol Biol Phys 54: $182-190$

Harris NL, Jaffe ES, Diebold J, Flandrin G, Muller-Hermelink HK, Vardiman J, Lister TA, Bloomfield CD (1999) World Health Organization Classification of neoplastic diseases of the hematopoietic and lymphoid tissues: report of the Clinical Advisory Committee Meeting - Airlie House, Virginia, November 1997. J Clin Oncol 17: 3835 - 3849

Harris NL, Jaffe ES, Stein H, Banks PM, Chan JK, Cleary ML, Delsol G, De Wolf-Peeters C, Falini B, Gatter KC (1994) A revised EuropeanAmerican classification of lymphoid neoplasm: a proposal from the International Lymphomas Study Group. Blood 84: 1361 - 1392

Hirakawa S, Kuyama M, Takahashi S, Yamasaki O, Kanzaki H, Teshima T, Harada M, Ma Y, Kawabata T, Yoshino T, Arata J (1999) Nasal and nasaltype natural killer/T-cell lymphoma. J Am Acad Dermatol 40: 268-272

Jaffe ES (1996) Classification of natural killer (NK) cell and NK-like T-cell malignancies. Blood 87: $1207-1210$

Jaffe ES, Chan JK, Su IJ, Frizzera G, Mori S, Feller AC, Ho FC (1996) Report of the workshop on nasal and related extranodal angiocentric $\mathrm{T} /$ natural killer cell lymphomas: definitions, differential diagnosis and epidemiology. Am J Surg Pathol 20: 103-111

Jaffe ES, Krenacs L, Kumar S, Kingma DW, Raffeld M (1999) Extranodal peripheral T-cell and NK-cell neoplasms. Am J Clin Pathol 111(Suppl 1): S46-S55

Kern WF, Spier CM, Hanneman EH, Miller TP, Matzner M, Grogan TM (1992) Neural cell adhesion molecule-positive peripheral T-cell lymphoma: a rare variant with a propensity for unusual sites of involvement. Blood 79: $2432-2437$

Kim BS, Kim TY, Kim CW, Kim JY, Heo DS, Bang YJ, Kim NK (2003) Therapeutic outcome of extranodal NK/T-cell lymphoma initially treated with chemotherapy. Acta Oncol 42: 779-783
In conclusion, we suggest that the anthracycline-based chemotherapy should not be used as a primary treatment for localised or advanced nasal-type NK/T cell lymphoma. Furthermore, because of the tendency of local failure for localised disease, the addition of radiation therapy to chemotherapy should be incorporated in a prospective trial. Nasal-type, NK/T cell lymphoma is a highly aggressive disease and the exploration for highly active drug is crucial to improve survival.

Kim GE, Cho JH, Yang WI, Chung EJ, Suh CO, Park KR, Hong WP, Park IY, Hahn JS, Roh JK, Kim BS (2000) Angiocentric lymphoma of the head and neck: patterns of systemic failure after radiation treatment. J Clin Oncol 18: $54-63$

Kim WS, Song SY, Ahn YC, Ko YH, Baek CH, Kim DY, Yoon SS, Lee HG, Kang WK, Lee HJ, Park CH, Park K (2001) CHOP followed by involved field radiation: is it optimal for localized nasal natural killer/T-cell lymphoma? Ann Oncol 12: 349-352

Ko YH, Cho EY, Kim JE, Lee SS, Huh JR, Chang HK, Yang WI, Kim CW, Kim SW, Ree HJ (2004) NK and NK-like T-cell lymphoma in extranasal sites: a comparative cllinicopathological study according to site and EBV status. Histopathology 44: $1-10$

Kobashi Y, Nakamura S, Sasajima Y, Koshikawa T, Yatabe Y, Kitoh K, Mori S, Ueda R, Yamabe H, Suchi T (1996) Inconsistent association of Epstein-Barr virus with CD56(NCAM)-positive angiocentric lymphoma occurring in sites other than the upper and lower respiratory tract. Histopathology 28: $111-120$

Lee KW, Kim DW, Im SA, Kim TY, Yoon SS, Heo DS, Bang YJ, Park S, Kim BK, Kim NK (2004) Efficacy of ifosfamide, methotrexate, etoposide and prednisone (IMEP) chemotherapy in extranodal NK/T cell lymphoma, nasal type. Proc Am Soc Clin Oncol 22: 603s (abstr 6685a)

Liang R, Todd D, Chan TK, Chiu E, Lie A, Kwong YL, Choy D, Ho FC (1995) Treatment outcome and prognostic factors for primary nasal lymphoma. J Clin Oncol 13: $666-670$

Mraz-Gernhard S, Natkunam Y, Hoppe RT, LeBoit P, Kohler S, Kim YH (2001) Natural killer/natural killer-like T-cell lymphoma, CD56+, presenting in the skin: an increasingly recognized entity with an aggressive course. J Clin Oncol 19: 2179-2188

Nakamura S, Suchi T, Koshikawa T, Kitoh K, Koike K, Komatsu H, Iida S, Kagami Y, Ogura M, Katoh E (1995) Clinicopathologic study of CD56 (NCAM) positive angiocentric lymphoma occurring in sites other than the upper and lower respiratory tract. Am J Surg Pathol 19: 284-296

Obama K, Tara M, Niina K (2003) L-asparaginase-based induction therapy for advanced extranodal NK/T-cell lymphoma. Int J Hematol 78: $248-250$

Peiper SC (1993) Angiocentric lymphoproliferative disorders of the respiratory system: incrimination of Epstein - Barr virus in pathogenesis. Blood 82: $687-690$

Wong KF, Chan JKC, Ng CS, Lee KC, Tsang WYW, Cheung MMC (1992) CD56 (NKH1)-positive hematolymphoid malignancies: an aggressive neoplasm featuring frequent cutaneous/mucosal involvement, cytoplasmic azurophilic granules and angiocentricity. Hum Pathol 23: $798-804$ 